\title{
Üniversite ögrencilerinin Akdeniz diyetine uyumu ve beslenme durumunun belirlenmesi
}

Tülay SÖNMEZ

\section{ÖZET}

Amaç: $\mathrm{Bu}$ çalışma üniversite öğrencilerinin beslenme alışkanlıkları ve Akdeniz diyetine uyumlarını belirlemeyi amaçlamaktadır. Yöntem: Hasan Kalyoncu Üniversitesi'nde eğitim gören, tesadüfi yöntemle belirlenmiş 739 gönüllü öğrenciye yüz yüze görüşme tekniğiyle anket formu uygulanmıștır. Bireylerin Akdeniz diyetine uyumları PREDIMED ölçeğiyle değerlendirilmiştir. Toplam puanı $\leq 5$ puan olanlar kötü, 6-9 puan geliştirilmeli, $\geq 10$ puan alanlar iyi olarak sınıflandırılmıştır. Bulgular: Çalışmaya katılan erkek ve kadın bireylerin beden kütle indeksi (BKİ) değeri ortalaması $24.0 \pm 3.4$ ve $21.8 \pm 3.3 \mathrm{~kg} / \mathrm{m}^{2}$ 'dir $(\mathrm{p}<0.05)$. Erkeklerin toplam PREDİMED puanı $7.4 \pm 1.9$ iken kadınların $7.8 \pm 1.9$ 'dur ( $>0.05$ ). PREDIMED testinden alınan toplam puana göre kötü, orta ve iyi derecede puan alan bireylerin oranı sirasıyla; \% $11.5, \% 73.3$ ve \%15.2'dir. BKİ sınıflaması normal olan bireylerin toplam puan ortalaması zayıf, hafif şişman ve obez olan bireylere göre daha fazladır $(\mathrm{p}<0.05)$. Bireylerin vücut ağırlı̆̆ , BKİ ve bel çevresi değeri ve ölçek puanı arasında negatif korelasyon bulunmaktadır. Sonuç: Normal vücut ağırlığına sahip bireylerin Akdeniz diyetine uyumları diğer BKİ aralığındaki bireylerden daha yüksektir. PREDIMED testi beslenme durumunun saptanmasında kullanılabilir bir ölçektir.

Anahtar kelimeler: Akdeniz diyeti, beden kütle indeksi, üniversite öğrencileri

\section{Determination of university student's adherence to the Mediterranean diet and dietary habits}

\begin{abstract}
Objective: This study was planned to determine the nutritional habits of university students and their adaptation to the Mediterranean diet. Methods: 739 volunteer students studying at Hasan Kalyoncu University were determined by a simple random method and a questionnaire form was applied to the individuals by face-to-face interview technique. Compliance of individuals to the Mediterranean diet was evaluated with the PREDIMED scale. Those who score 5 points in total are poor, 69 points should be improved, those who score 10 points were classified as good. Results: The average body mass index (BMI) value of male and female individuals participating in the study is $24.0 \pm 3.4$ and $21.8 \pm 3.3 \mathrm{~kg} / \mathrm{m} 2(\mathrm{p}<0.05)$. While the total PREDIMED score of men is $7.4 \pm 1.9$, it is $7.8 \pm 1.9$ for women $(\mathrm{p}>0.05)$. According to the total score obtained from the PREDIMED test, the ratio of individuals who got bad, moderate and good scores, respectively; $11.5 \%, 73.3 \%$ and $15.2 \%$. Individuals with normal BMI classification have a higher average score than that of individuals who are thin, slightly obese and obese $(\mathrm{p}<0.05)$. There is a negative correlation between individuals body weight, BMI, waist circumference and scale score. Conclusion: Compliance of individuals with normal body weight to Mediterranean diet is higher than individuals in other BMI ranges. PREDIMED test is a scale that can be used to determine nutritional status.
\end{abstract}

Keywords: Mediterranean diet, body mass index, university students

\footnotetext{
Geliș Tarihi: 12.02.2021 Kabul Tarihi:10.04.2021

aSerbest Yazar, İstanbul, Türkiye, e-posta: tulayysonmez@gmail.com ORCID: 0000-0002-1536-1744

Sorumlu Yazar/Correspondence: Tülay Sönmez e-posta: tulayysonmez@gmail.com

Atıf: Sönmez T. Üniversite öğrencilerinin Akdeniz diyetine uyumu ve beslenme durumunun belirlenmesi. Sağllk ve Yaşam Bilimleri Dergisi 2021;3(1):85-90.

Citation: Sonmez T. Determination of university student's adherence to the Mediterranean diet and dietary habits. Journal of Health and Life Science 2021;3(1):85-90.
} 


\section{GíRiş}

Akdeniz diyeti Güney İtalya ve Akdeniz bölgesinde yer alan bireylerin yaşam tarzının genel adıdır. ${ }^{1} \mathrm{Bu}$ diyet anlayışı UNESCO tarafından 2010 yılında "İnsanlığın Somut Olmayan Kültürel Mirası" olarak kabul edilmiştir. ${ }^{2} \mathrm{Bu}$ beslenme tarzının iki ana ögesi sebze ve zeytinyağıdır. ${ }^{3}$ Bunun yanında yüksek miktarda kuru baklagiller, meyve, sebze ve rafine edilmemiş tahıl tüketiminin, kırmızı et tüketimi yerine beyaz et tüketiminin benimsendiği ve süt tüketiminin temel ilke sayıldığ bir beslenme tarzıdır. ${ }^{4} \mathrm{Bu}$ beslenme tarzında orta düzeyde şarap tüketimi de yer almaktadır. ${ }^{5}$ Akdeniz diyetinin tek formu yoktur, bu bölgede yer alan her ülke kendi kültürüne uyumlu olarak bu beslenme tarzının çeşitli formlarını uygulamaktadır. ${ }^{6}$
Akdeniz diyetinin 2010 y1lında sürdürülebilir diyet olduğu vurgulanmıştır. Sürdürülebilir diyetler; ekonomik, beslenme bakımından yeterli ve güvenli, ekosistem koruyucu ve kültürel olarak kabul edilip uygulanabilir olarak tanımlanmıştır. ${ }^{7}$ Güncel beslenme alışkanlıkları baz alınarak 2010 yılı içerisinde bir Akdeniz Beslenme Piramidi hazırlanmıştır. $\mathrm{Bu}$ piramitte porsiyon tüketimi, tüketim sıklığı da yer almaktadır. Aynı zamanda piramidin tabanını fazla tüketilmesi gereken besin grupları oluştururken, piramitte yukarılara doğru tüketilmesi daha az önerilen besin ve besin grupları yer almıştır. Piramit tabanında fiziksel aktivite gerekliliği de vurgulanmıştır (Şekil 1). ${ }^{2}$

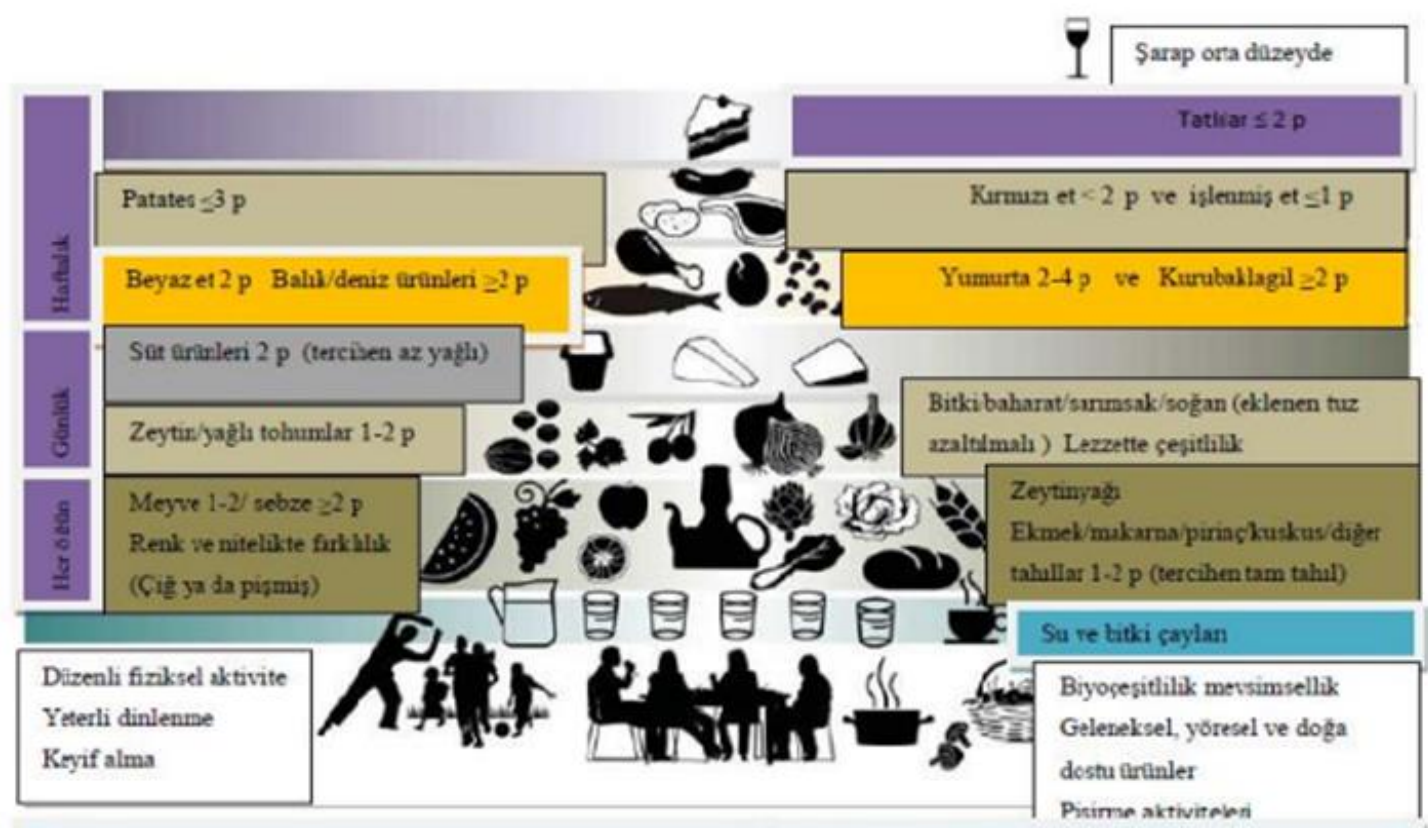

\section{Şekil 1. Güncel Akdeniz piramidi}

Akdeniz diyetinin, obezite ile ilişkili hastalıkların önlenmesinde etkili olduğu kanıtlanmıştır. ${ }^{8,9}$ Besinlerin tüketim sıklığı ve miktarı açısından yetişkin bireylerde daha düşük kardiyovasküler mortalite ve koroner hastal1k, obezite, tip 2 diyabet ve metabolik sendrom riski ile ilişkilendirilmiştir. ${ }^{10-13}$ Uzun vadeli vücut ağırlığı kaybında Akdeniz diyetinin rolünü inceleyen bir çalışmanın sonucunda vücut ağırlığ kaybı programı uygulayan, fazla kilolu veya obez bireylerde uygun sonuçlar verdiği ve kardiyovasküler risk faktörü seviyesinde azalma meydana getirdiği saptanmıştır. ${ }^{14}$

Akdeniz diyeti tip 2 diyabet, hipertansiyon, dislipidemi gibi hastalıkların görülme durumunu azalttığı ve dolaylı olarak Alzheimer hastalığının da görülme riskini azaltması ile ilişkilendirilmektedir. Ayrıca, oksidatif stres Alzheimer hastalığının önemli sebeplerindendir ve bu diyet tarzının antioksidan içeriğinin zengin olması oksidatif stresin engellenmesi sağlamaktadır. Akdeniz diyetinin inflamasyon azaltıcı etkisi Alzheimer hastalığının olası başka bir mekanizması olan inflamatuar sürecin önlenmesini sağlayabileceği düşünülmektedir. ${ }^{15-17} \mathrm{Bu}$ çalışma, üniversite öğrencilerinin beslenme alışkanlıkları ve Akdeniz diyetine uyumlarını belirlemeyi amaçlamaktadır.

\section{YÖNTEM}

Çalışma, üniversite öğrencilerinin beslenme alışkanlıkları ve Akdeniz diyetine uyumlarını belirlenmesi amacıyla planlanmıştır. Çalışmanın evrenini 2016-2017 y1lında Hasan Kalyoncu 
Üniversitesinde eğitim gören 3328 ön lisans ve lisans öğrencilerinin tümü oluşturmuştur. Çalışma örneklemi ise Raosoft Sample Size Calculator programı ile evren sayısı kullanılarak hesaplanmış ve minimum 345 birey olarak belirlenmiştir. Araştırmada \%95 güven aralığı ve $\% 5$ hata payı kabul edilmiştir. Çalışmanın gerçekleştirilebilmesi için Hasan Kalyoncu Üniversitesi'nden 97914692/17 numaralı Etik Kurul Onayı alınmıştır. Çalışmaya katılmayı kabul eden bireyler basit tesadüfi yöntemle belirlenmiş ve bireylere yüz yüze görüşme tekniğiyle anket formu uygulanmıştır. Hasan Kalyoncu Üniversitesinde 20162017 yılında ön lisans ve lisans bölümünde eğitim gören, çalışmaya katılmayı gönüllü olarak kabul eden ve 18 yaşından büyük öğrenciler çalışmaya dahil edilirken bu kapsamda olmayanlar çalışmanın dışında tutulmuştur. Anket formunu doldurmayı kabul eden bireylere çalışmayla ilgili bilgi verilip aydınlatılmış onam formu imzalatılmıştır.

Kullanılan anket formunda bireylerin demografik özelliklerinin yanında PREDİMED ölçeği de uygulanmıştır. $\mathrm{Bu}$ ölçekte toplamda 14 soru bulunmaktadır. Soruların 12 tanesi besin tüketim sıklığı, 2 tanesi besin tüketim alışkanlıklarıyla ilgilidir. Ölçekten toplamda 0-14 arasında puan alınmaktadır. Toplam puanı $\leq 5$ puan olanlar kötü, 6-9 puan geliştirilmeli, $\geq 10$ puan alanlar iyi olarak sınıflandırılmıştır. ${ }^{18}$

Veriler SPSS 22 programında analizi yapılmak üzere kaydedilmiştir. Anketlerden elde edilen sürekli değişkenler ortalama $(\bar{x})$, standart sapma (SS), alt-üst ile kategorik değişkenler sayı (n) ve yüzde (\%) olarak ifade edilmiştir. Kategorik değişkenlerde gruplar arasındaki ilişkinin analizi ki kare testi, sürekli değişkenlerin normal dağılma uygunlukları Kolmogov-Simirnov testi ile analiz edilmiştir. Normal dağılıma uygun olan verilerde iki grup arasındaki anlamlılığın analizi için $\mathrm{t}$ testi, ikiden fazla grup arasındaki anlamlılığın analizi için Anova testi, normal dağılıma uygun olmayan verilerde iki grup arasındaki anlamlılığın analizi için Mann Whitney $\mathrm{u}$ testi kullanılmıştır. ${ }^{19}$
Tablo 1. Bireylerin genel özellikleri

\begin{tabular}{lcc}
\hline & n & \% \\
\hline Cinsiyet & \multicolumn{2}{c}{33.0} \\
Erkek & 495 & 67.0 \\
Kadın & $21.7 \pm 2.4$ \\
Yaş (yıl) $\bar{x} \pm$ SS & \multicolumn{2}{c}{} \\
Öğrenim gördüğ̈̈ fakülte & 273 & 36.9 \\
Sağlı Bilimleri Fakültesi & 466 & 63.1 \\
Diğer fakülteler & & \\
Öğrenim gördü̆ğü bölüm & 116 & 15.7 \\
Beslenme ve diyetetik & 623 & 84.3 \\
Diğgr bölümler & & \\
Sigara kullanma durumu & 204 & 27.6 \\
Evet & 535 & 72.4 \\
Hayır & $6.7 \pm 9.2$ \\
Günlük içilen sigara adedi $(\overline{\boldsymbol{x}} \pm$ SS) & \multicolumn{2}{c}{13.4} \\
Alkol kullanma durumu & 99 & 13.4 \\
Evet & 640 & 86.6 \\
Hayır & \multicolumn{2}{|c}{} \\
Düzenli egzersiz yapma durumu & 167 & 22.6 \\
Evet & 572 & 77.4 \\
Hayır & $2.4 \pm 0.6$ \\
Ana öğ̈ün sayısı & \multicolumn{2}{c}{$1.6 \pm 1.0$} \\
Ara öğün sayısı &
\end{tabular}

\section{BULGULAR}

Çalışmaya katılan bireylerin 33'ü erkek \%67'si kadındır. Yaş ortalaması ise $21.7 \pm 2.4$ yıldır. Üniversitenin sağlık bilimleri fakültesinde eğitim gören bireylerin oranı \%36.9 iken diğerlerinin oranı $\% 63.1$ 'dir. Okunan fakülte haricinde daha detaylı olarak incelendiğinde bir beslenme profesyoneli olacak olan Beslenme ve Diyetetik öğrencilerinin oranı $\% 15.7$ 'dir. Öğrencilerin \%27.6's1 sigara, \%13.4'ü alkol kullandığını, \%22.6'sı ise düzenli fiziksel aktivite yaptığını belirtmiştir. Günlük tüketilen ana ve ara öğünlerin ortalaması $2.4 \pm 0.6$ ve $1.6 \pm 1.0$ ' dir (Tablo 1). Bireylerin antropometrik değerlerinin ortalamaları verilmiştir. Erkeklerin BKİ değeri ortalaması 24 \pm 3.4 $\mathrm{kg} / \mathrm{m}^{2}$ iken kadınların $21.8 \pm 3.3 \mathrm{~kg} / \mathrm{m}^{2}$ ' dir $(\mathrm{p}<0.05)$. Bel çevresi değeri ortalaması erkek ve kadınlarda sirasiyla; $86.4 \pm 10.3 \mathrm{~cm}$ ve $73.1 \pm 11.2 \mathrm{~cm}$ 'dir $(\mathrm{p}<0.05)$. Erkeklerin bel boy oranı ortalaması $0.5 \pm 0.1$ iken kadinların 0.4 \pm 0.1 'dir (Tablo 2).

Tablo 2. Bireylerin antropometrik ölçüm değerleri

\begin{tabular}{|c|c|c|c|c|c|c|c|}
\hline & \multicolumn{3}{|c|}{ Erkek } & \multicolumn{3}{|c|}{ Kadın } & \multirow{2}{*}{$\underset{\text { değeri }}{p}$} \\
\hline & $\overline{\boldsymbol{x}} \pm \mathrm{SS}$ & Alt & Üst & $\overline{\boldsymbol{x}} \pm \mathrm{SS}$ & Alt & Üst & \\
\hline Boy uzunluğu (cm) & $178.2 \pm 6.6$ & 160.0 & 196.0 & $165.2 \pm 5.9$ & 150.0 & 185.0 & 0.000 \\
\hline Vücut ağırlığı (kg) & $76.4 \pm 11.7$ & 50.0 & 119.0 & $59.4 \pm 9.9$ & 39.0 & 110.0 & 0.000 \\
\hline BKİ (kg/m²) & $24.0 \pm 3.4$ & 16.3 & 37.2 & $21.8 \pm 3.3$ & 15.2 & 40.0 & 0.000 \\
\hline Bel çevresi (cm) & $86.4 \pm 10.3$ & 64.0 & 120.0 & $73.1 \pm 11.2$ & 50.0 & 125.0 & 0.000 \\
\hline Bel/Boy Oranı (cm) & $0.5 \pm 0.1$ & 0.1 & 0.7 & $0.4 \pm 0.1$ & 0.3 & 0.8 & 0.000 \\
\hline
\end{tabular}


Tablo 3. Bireylerin cinsiyete göre antropometrik ölçüm değerlerinin sınıflaması

\begin{tabular}{|c|c|c|c|c|c|}
\hline & \multicolumn{2}{|c|}{ Erkek } & \multicolumn{2}{|c|}{ Kadın } & \multirow{2}{*}{$\underset{\text { değeri }}{p}$} \\
\hline & $\mathbf{n}$ & $\%$ & $\mathbf{n}$ & $\%$ & \\
\hline \multicolumn{6}{|c|}{ BKİ sınıflandırması } \\
\hline Zayıf & 6 & 2.5 & 49 & 9.9 & \multirow{4}{*}{0.000} \\
\hline Normal & 167 & 68.4 & 390 & 78.8 & \\
\hline Hafif şişman & 55 & 22.5 & 45 & 9.1 & \\
\hline Obez & 16 & 6.6 & 11 & 2.2 & \\
\hline \multicolumn{6}{|c|}{ Bel Çevresi Risk Sınıflaması } \\
\hline Normal & 184 & 75.4 & 369 & 74.5 & \multirow{3}{*}{0.276} \\
\hline Risk & 46 & 18.9 & 82 & 16.6 & \\
\hline Yüksek Risk & 14 & 5.7 & 44 & 8.9 & \\
\hline \multicolumn{6}{|c|}{ Bel Kalça oranı sınıflaması } \\
\hline Normal & 146 & 59.8 & 405 & 81.8 & \multirow[b]{2}{*}{0.000} \\
\hline Risk & 98 & 40.2 & 90 & 18.2 & \\
\hline
\end{tabular}

Tablo 4. Bireylerin toplam PREDIMED puanı ortalaması ve sınıflaması

\begin{tabular}{|c|c|c|c|c|c|c|c|}
\hline & \multicolumn{2}{|c|}{ Erkek } & \multicolumn{2}{|c|}{ Kadın } & \multicolumn{2}{|c|}{ Toplam } & \multirow{2}{*}{$\underset{\text { değeri }}{p}$} \\
\hline & $\mathbf{n}$ & $\%$ & $\mathbf{n}$ & $\%$ & $\mathbf{n}$ & $\%$ & \\
\hline \multicolumn{8}{|l|}{ PREDİMED Sınıflaması } \\
\hline Kötü (0-5 puan) & 34 & 13.9 & 51 & 10.3 & 85 & 11.5 & \multirow{3}{*}{0.049} \\
\hline Orta (6-9 puan) & 183 & 75.0 & 359 & 72.5 & 542 & 73.3 & \\
\hline İyi (10-14 puan) & 27 & 11.1 & 85 & 17.2 & 112 & 15.2 & \\
\hline Toplam PREDİMED puanı & \multicolumn{2}{|c|}{$7.4 \pm 1.9$} & \multicolumn{2}{|c|}{$7.8 \pm 1.9$} & \multicolumn{2}{|c|}{$7.7 \pm 1.9$} & 0.011 \\
\hline
\end{tabular}

Bireylerin cinsiyete göre antropometrik ölçüm sinıflamaları verilmiştir. Bu tabloda yer alan verilere göre; erkeklerin \%6'sı kadınların \%9.9'u zayıftır. Erkek ve kadınlarda obez olma oranı sırasıyla; \%6.6 ve \%2.2’dir. Erkeklerin zayıf olma oranı kadınlara göre daha azdır ve bu sonuç istatistiksel olarak anlamlıdır $(\mathrm{p}<0.05)$. Bel çevresi yüksek risk grubunda olan erkeklerin oranı \%5.7 iken kadınların \%8.9'dur. Bel kalça oranı risk grubunda olan erkeklerin oranı kadınlardan fazladır $(\mathrm{p}<0.05)$ (Tablo 3).

Tablo 5. Bireylerin özelliklerine göre PREDİMED puanı ortalaması

\begin{tabular}{|c|c|c|c|c|}
\hline Özellikler & & $\bar{x}$ & $\mathbf{S}$ & $\underset{\text { değeri }}{\mathbf{p}}$ \\
\hline \multirow{2}{*}{ Öğrenim görülen fakülte } & Sağlık Bilimleri Fakültesi & 8.2 & 1.6 & \multirow{2}{*}{0.000} \\
\hline & Diğer fakülteler & 7.4 & 2.0 & \\
\hline \multirow{2}{*}{ Öğrenim görülen bölüm } & Beslenme ve Diyetetik & 8.6 & 1.4 & \multirow{2}{*}{0.000} \\
\hline & Diğer bölümler & 7.5 & 1.9 & \\
\hline \multirow{2}{*}{ Sigara içme durumu } & Evet & 7.5 & 1.8 & \multirow{2}{*}{0.292} \\
\hline & Hayır & 7.7 & 1.9 & \\
\hline \multirow[b]{2}{*}{ Alkol kullanma durumu } & Evet & 7.5 & 1.9 & \multirow{2}{*}{0.329} \\
\hline & Hayır & 7.7 & 1.9 & \\
\hline \multirow{2}{*}{$\begin{array}{l}\text { Düzenli fiziksel aktivite } \\
\text { yapma durumu }\end{array}$} & Evet & 7.6 & 1.8 & \multirow{2}{*}{0.676} \\
\hline & Hayır & 7.7 & 1.9 & \\
\hline \multirow{4}{*}{ BKİ sınıflaması } & Zayif & 7.2 & 1.8 & \multirow{4}{*}{0.001} \\
\hline & Normal & 7.8 & 2.0 & \\
\hline & Hafif şişman & 7.2 & 1.4 & \\
\hline & Obez & 7.1 & 1.6 & \\
\hline \multirow{3}{*}{ Bel çevresi sınıflaması } & Normal & 7.7 & 1.9 & \multirow{3}{*}{0.330} \\
\hline & Risk & 7.6 & 1.9 & \\
\hline & Yüksek risk & 7.3 & 1.7 & \\
\hline \multirow{2}{*}{ Bel/boy oranı sınıflaması } & Normal & 7.7 & 1.9 & \multirow{2}{*}{0.085} \\
\hline & Risk & 7.5 & 1.8 & \\
\hline
\end{tabular}


PREDİMED testinden alınan toplam puana göre kötü, orta ve iyi derecede puan alan erkeklerin oranı sirasiyla; \%13.9, \%75 ve \%11.1 iken bu oranlar kadınlarda; \%10.3, \%72.5 ve \%17.2'dir. PREDIMED puanı iyi olan kadınların oranı erkeklerden fazladır ve bu sonuç istatistiksel olarak anlamlıdır. Erkeklerin toplam PREDİMED puanı $7.4 \pm 1.9$ iken kadınların $7.8 \pm 1.9$ 'dur $(\mathrm{p}<0.05)$ (Tablo 4).

Sağlık bilimleri fakültesinde eğitim gören bireylerin toplam ölçek puanı ortalaması $8.2 \pm 1.6$ iken diğer fakültelerinki $7.4 \pm 2$ 'dir $(\mathrm{p}<0.05)$. Beslenme ve diyetetik bölümü öğrencilerinin puan ortalaması 7.5 \pm 1.9 'dur $(\mathrm{p}<0.05)$. Sigara, alkol kullanma ve düzenli fiziksel aktivite yapma durumunun ölçek puanı ortalamasında anlamlı bir farkı bulunmamaktadır (p>0.05). BKİ siniflaması normal olan bireylerin toplam puan ortalaması zayıf, hafif şişman ve obez olan bireylere göre daha fazladır $(\mathrm{p}<0.05)$ (Tablo 5).

Bireylerin vücut ağırlığı, BKİ ve bel çevresi değeri arttıkça ölçek puanı azalmaktadır. Bu değerlerin ölçek puanıla arasında negatif korelasyon bulunmaktadır (Tablo 6).

Tablo 6. Bireylerin PREDİMED puanının bazı parametrelerle korelasyonu

\begin{tabular}{lcc} 
& \multicolumn{2}{c}{ PREDİMED Puanı } \\
\hline Yaş (yıl) & $\mathrm{R}$ & $\mathrm{p}$ \\
\hline Vücut ağırlığı (kg) & -0.014 & 0.712 \\
BKİ (kg/m²) & -0.099 & $\mathbf{0 . 0 0 7}$ \\
Bel çevresi (cm) & -0.080 & $\mathbf{0 . 0 3 0}$ \\
Bel boy oranı & -0.078 & $\mathbf{0 . 0 3 4}$ \\
\hline
\end{tabular}

\section{TARTISMA}

Kore'de yapılan National Health and Nutrition Examination araştırmasının sonucunda Akdeniz diyet skoru yüksek olan bireylerin metabolik sendrom prevelansının daha az olduğu belirlenmiştir. ${ }^{20}$ Akdeniz diyetinin kardiyovasküler hastalıklar üzerine ilişkisini inceleyen bir çalışmada karotis arter darlığ $1 \% 60$ 'dan fazla olan ve \%60'dan az olan ve aterosklereotik hastalığı bulunmayan bireyler olmak üzere üç gruba ayrılmış ve bireylerin Akdeniz diyet skoru belirlenmiştir. Diyet skoru sıralaması; hastalığı olmayan bireyler $>$ KAD \%60'dan az olan $>$ KAD $\%$ 60'dan fazla olan olarak saptanmıştır. ${ }^{21}$ Bir başka çalışmada da yine Akdeniz diyetinin koroner ateroskleroz şiddetini azaltmaya yardımcı olduğu belirlenmiştir. ${ }^{22}$ Karaban ve ark. çalışmasında Akdeniz diyetine uyumunun artırılması, obezite ve obezite ile ilişkili hastalık riskinin azalmasına yardımcı olduğunu belirtmiştir. $^{23}$ İspanya'da yapılan bir çalışmada da Akdeniz diyetinin yağdan kısıtlı bir diyete oranla bireylerin BKİ ve bel çevrelerinde iyileşme gösterdiği belirtilmiştir. $^{24}$ Tip 2 diyabet ve kardiyovasküler hastalığa sahip bireyler üzerinde uygulanan kuruyemiş ile zenginleștirilmiș Akdeniz diyetinin fazla kilolu ve obez bireylerde yağdan fakir diyetlere göre tercih edilebilir olduğu belirtilmiştir. ${ }^{25}$ PREDIMED çalışma sonuçları, yüksek doymamış yağ ve antioksidan açısından zengin diyet modelinin kardiyovasküler hastalıkların önlenmesinde yararlı bir araç olduğunu göstermiştir. ${ }^{26}$ Bir başka çalışmada da benzer olarak Akdeniz diyetinin kardiyovasküler hastalıkların, diyabetin birincil korunmasında ve metabolik sendromun yönetiminde faydalı etkileri olduğu belirlenmiştir. ${ }^{27}$ Bir araştırmada, fındık ile takviye edilmiş bir Akdeniz diyetinin Tip 2 diyabeti olan hastalarda depresyon riski üzerinde yararlı bir etki yaratabileceği belirtilmiştir. ${ }^{28}$

Lise ve üniversite öğrencileri arasında yapılan bir araştırma sonucunda bireylerin Akdeniz diyetine uyum puanı $4.1 \pm 2.4$ olarak bulunmuştur. $\mathrm{Bu}$ araştırmada bizim çalışmamızdan farklı olarak ölçek puanı ve antropometrik değerler arasında bir korelasyon bulunmamıştır. ${ }^{29}$ Rize'de üniversite çalışanları arasında yapılan çalışmada bireylerin toplam ölçek puanı ortalaması $7.3 \pm 0.1$ olarak saptanmıştır. $\mathrm{Bu}$ çalışmada Sağlık Bilimleri Fakültesi çalışanlarının puan ortalaması $6.9 \pm 0.2$ iken diğer fakültelerde bu puan ortalaması $75 \pm 0.1$ olarak bulunmuştur. ${ }^{30}$ Farklı illerde yaşayan 19-49 yaş grubu bireylerin dahil olduğu bir çalışmada erkek ve kadınların ölçekten aldıkları puan ortalaması $6.4 \pm 2$ ve $7 \pm 1.9$ olarak belirlenmiştir. Ayrıca bu çalışmada bizim de çalışmamızı yürüttüğümüz il olan Gaziantep $7.7 \pm 1.7$ puan ortalamasıyla en yüksek puan ortalamasına sahip il olmuştur. ${ }^{31}$ Yaklaşık yedi bin katılımcının olduğu bir çalışmada bireylerin PREDIMMED puan ortalaması $8.6 \pm 2.7$ olarak bulunmuştur. ${ }^{32}$ Sicilya' da yapılan bir çalışmada normal vücut ağırlığına sahip bireylerin Akdeniz diyetine uyumları daha fazla bulunmuştur. ${ }^{33}$ İtalya'da obez kadın bireylerin katılımıyla gerçekleştirilen bir çalışmada bireylerin Akdeniz diyetine uyumlarının artması sağlanmış ve çalışmanın sonucunda bireylerin vücut ağırlığı ve BKI değerlerinde anlamlı şekilde azalmalar saptanmıştır. ${ }^{34}$ Uzun süreli bir kohort çalışmasının sonucunda bireylerin Akdeniz diyetine uyumlarının artmasıyla obezite riskinin ve bel çevresi yağlanmasının azaldığı belirlenmiştir. ${ }^{35}$ Erişkin bireyler üzerinde yapılan bir araştırmanın sonucunda Akdeniz diyetine uyum arttıkça bireylerin yağ kütlesi, bel ve kalça çevresinde anlamlı azalma olduğu belirlenmiştir. ${ }^{36}$ Akdeniz diyetine uyumun yüksek ve düşük olduğu kişilerin beslenme durumlarının kıyaslandığı bir çalışmada, Akdeniz diyetine uyumun yüksek olduğu gruptaki bireylerin vücut ağırlığı, BKİ, bel çevresi değerinin diğer gruba göre anlamlı şekilde daha düşük olduğu saptanmıştır. ${ }^{37}$ Sahrai ve arkadaşlarının 34-69 yaş aralığındaki kadınlarla yaptığı çalışmada Akdeniz diyetine uyum ile bel çevresi arasında ilişki olduğunu belirtmiştir. $^{38}$

\section{SONUÇ}

Çalışmamızda Akdeniz diyetinin vücut ağırlığı, BKİ 
üzerine olumlu etkileri mevcuttur. $\mathrm{Bu}$ diyetin uyumunun ölçülmesinde bir kriter olan PREDIMMED ölçeği de kullanılabilir olumlu bir ölçektir. Akdeniz diyeti obezite tedavisinde kullanılabilen bir diyet türüdür.

\section{KAYNAKLAR}

1. Davis C, Bryan J, Hodgson J, Murphy K. Definition of the Mediterranean diet; a literature review. Nutrients. 2015;7(11):9139-9153.

2. Bach-Faig A, Berry EM, Lairon D, et al. Mediterranean diet pyramid today. Science and cultural updates. Public Health Nutrition. 2011;14(12A):2274-2284.

3. Yannakoulia M, Kontogianni M, Scarmeas N. Cognitive health and Mediterranean diet: just diet or lifestyle pattern. Ageing Res Rev. 2015;20:74-78.

4. Serra-Majem L, Ortiz-Andrellucchi A. The Mediterranean diet as an example of food and nutrition sustainability: a multidisciplinary approach. Nutr Hosp. 2018;35(4):96-101.

5. Naska A, Trichopoulou A. (2014). Back to the future: the Mediterranean diet paradigm. Nutrition, Metabolism, and Cardiovascular Diseases. 2014;24(3): 216-219.

6. Gerber M, Hoffman R. The Mediterranean diet: health, science and society. Br J Nutr. 2015;113(2):4-10.

7. Burlingame B, Dernini S. Sustainable diets: the Mediterranean diet as an example. Public Health Nutrition. 2011;14(12A):2285-2287.

8. Ersoy G, Özdemir G. The benefits of Mediterranean Diet to health. Turkiye Klinikleri J Cardiovasc Sci. 2010;22(1):75-84.

9. Martínez-González MÁ, Sánchez-Villegas A. The emerging role of Mediterranean diets in cardiovascular epidemiology: Monounsaturated fats, olive oil, red wine or the whole pattern. Eur J Epidemiol. 2004;19:9-13.

10. Sofi F, Macchi C, Abbate R, Gensini GF, Casini A. Mediterranean diet and health status: an updated metaanalysis and a proposal for a literature-based adherence score. Public Health Nutr. 2014;17: 2769-2782.

11. D'Alessandro A, De Pergola G. The Mediterranean Diet: its definition and evaluation of a priori dietary indexes in primary cardiovascular prevention. Int $J$ Food Sci Nutr. 2018;69(6):647-659.

12. D'Innocenzo S, Biagi C, Lanari M. (2019). Obesity and the Mediterranean Diet: a review of evidence of the role and sustainability of the Mediterranean diet. Nutrients. 2019;11(6):1306.

13. Romagnolo DF, Selmin OI. Mediterranean diet and prevention of chronic diseases. Nutr Today. 2017;52:208-222.

14. Rosato V, Temple NJ, La Vecchia C, Castellan G, Tavani A, Guercio V. Mediterranean diet and cardiovascular disease: a systematic review and metaanalysis of observational studies. Eur. J. Nutr. 2019;58(1):173-191.

15. Mancini JG, Filion KB, Atallah R, Eisenberg MJ. Systematic review of the Mediterranean diet for longterm weight loss. Am J Med. 2016;129(4): 407-415.

16. Miranda A, Gómez-Gaete C, Mennickent S. Role of Mediterranean diet on the prevention of Alzheimer disease. Rev Med Chil. 2017;145(4):501-507.

17. Santa D, Carlotta B, Marcello L. Obesity and the Mediterranean diet: a review of evidence of the role and sustainability of the Mediterranean diet. Nutrients. 2019;11(6):1306.

18. Martinez-Gonzalez MA, Garcia-Arellano A, Toledo E, et al. A 14-item Mediterranean diet assessment tool and obesity indexes among high-risk subjects: the PREDIMED trial. PloS One. 2012;7(8):43134.

19. Sümbüloğlu K, Sümbüloğlu V. Biyoistatistik. Hatipoğlu Yayınevi, Ankara, 2016.

20. Kim Y, Je Y. A modified Mediterranean diet score is inversely associated with metabolic syndrome in Korean adults. Eur J Clin Nutr. 2018;72(12):1682-1689.

21. Kuyumcu A, Kuyumcu M. Akdeniz diyeti ve karotis arter hastalığı arasındaki ilişki. Süleyman Demirel Üniversitesi Sağllk Bilimleri Dergisi. 2019;10(2):99104.

22. Akgüllü Ç, Sırıken F, Eryılmaz U, et al. The relation between compliance to the Mediterranean diet and the extensiveness of coronary artery disease. Archives of the Turkish Society of Cardiology. 2015;43(4):340-349.

23. Kabaran S, Gezer C. Kuzey Kıbrıs Türk Cumhuriyeti'ndeki çocuk ve adölesanlarda Akdeniz diyetine uyum ile obezitenin belirlenmesi. Türkiye Çocuk Hastalıkları Dergisi. 2013;7(1):11-20.

24. Cueto-Galán R, Barón FJ, Valdivielso P, et al. Changes in fatty liver index after consuming a Mediterranean diet: 6-year follow-up of the PREDIMED-Malaga trial. Med Clin (Barc). 2017;148(10):435-443.

25. Álvarez-Pérez J, Sánchez-Villegas A, Díaz-Benítez EM, et al. Influence of a Mediterranean dietary pattern on body fat distribution: results of the PREDIMMEDCanarias Intervention Randomized Trial. Am Coll Nutr. 2016;35(6):568-580.

26. Ros E, Martínez-González MA, Estruch R, et al. Mediterranean diet and cardiovascular health: teachings of the PREDIMED study. Adv Nutr. 2014;14;5(3):330S$6 \mathrm{~S}$.

27. Kargin D, Tomaino L, Serra-Majem L. Experimental outcomes of the Mediterranean diet: lessons learned from the predimed randomized controlled trial. Nutrients. 2019;11(12):2991.

28. Sánchez-Villegas A, Martínez-González MA, Estruch $\mathrm{R}$, et al. (2013). Mediterranean dietary pattern and depression: the PREDIMED randomized trial. $B M C$ Med. 2013;11:208.

29. Bayındır GA, Yardımcı H. Öğrencilerin ev dışı ana öğün tüketimlerine ve antropometrik ölçümlerine göre Akdeniz diyet uyumlarının incelenmesi. STED / Sürekli Tıp Ĕ̈itimi Dergisi. 2019;28(6);403-397.

30. Okur A, Karaoğlu L. Üniversite çalışanlarının beslenme alışkanlıkları ve etki eden bireysel ve iş çevresi faktörleri. 3.International 21.National Public Health Congress, 2019.

31. Çam M, Büyükdere $Y$, Bozoğlan H, et al. Değişik illerde yaşayan 19-49 yaş grubu yetişkin bireylerde Akdeniz diyetine uyumun saptanmas1. 9. Uluslararas1 Beslenme ve Diyetetik Kongresi: 2-5 Nisan, Ankara, Türkiye 2014.

32. Sayón-Orea C, Razquin C, Bulló M, et al. Effect of a nutritional and behavioral intervention on energyreduced Mediterranean diet adherence among patients with metabolic syndrome: interim analysis of the PREDIMED-Plus randomized clinical trial. JAMA. 2019;322(15):1486-1499.

33. Metro D, Tardugno R, Papa M, et al. Adherence to the Mediterranean diet in a Sicilian student population. Nat Prod Res. 2018;32(15):1775-1781 
34. Franquesa M, Pujol-Busquets G, Garcia-Fernandez E, et al. Mediterranean diet and cardiodiabesity: a systematic review through evidence-based answers to key clinical questions. Nutrients. 2019;11(3):655.

35. Agnoli C, Sieri S, Ricceri F, et al. Adherence to a Mediterranean diet and long-term changes in weight and waist circumference in the EPIC-Italy cohort. Nutrition \& Diabetes. 2018;8(1):22.

36. Aşit M. Yetişkin bireylerde Akdeniz diyet skoru ile beslenme alışkanlıkları ve antropometrik ölçümler arasındaki ilişkinin değerlendirilmesi. Trakya Üniversitesi Sosyal Bilimler Enstitüsü, 2019.
37. Esposito K, Maiorino MI, Di Palo C, Giugliano D. Adherence to a Mediterranean diet and glycaemic control in type 2 diabetes mellitus. Diabetic Medicine. 2009;26(9):900-907.

38. Sahrai MS, Huybrechts I, Biessy C, et al. Association of a priori-defined dietary patterns with anthropometric measurements: a crosssectional study in Mexican women. Nutrients. 2019;11(3):603. 